\title{
Modulation of Pain by Naloxone and a Possible Role of Neurotransmitters with Selective Lesion of Septal Nuclei
}

\section{Prakash M. Somade ${ }^{1 *}$ Atul R. Chopade ${ }^{2}$ and Shivaji V. Brid ${ }^{1}$}

${ }^{1}$ Department of Physiology, Krishna Institute of Medical Sciences, Karad, 415539, Maharashtra, India

${ }^{2}$ Department of Pharmacology, Rajarambapu College of Pharmacy, Kasegaon 415404, Maharashtra, India

\begin{abstract}
Septum occupies a strategic position in limbic system and has been implicated in variety of behaviors. Present study was designed to evaluate the role of medial septum in modulation of pain and explore the role of neurotransmitters.

The present study was divided in two parts in first part the tail flick latencies were observed in rats with septal lesions and compared with sham operated ones. While in the second part, the effect of intraseptal injections of neurotransmitters and naloxone on tail flick latencies ofcannulated rats was recorded after intraseptal lesions.

It was observed that the septal lesions decrease pain threshold. The interaseptal injection of Acetylcholine $(5 \mu \mathrm{g}$ to $20 \mu \mathrm{g})$ and Naloxone $(5 \mu \mathrm{g}$ to $20 \mu \mathrm{g})$ increases pain threshold. While the Interaseptal injection of Noradrenaline and Scopolamine decreases pain threshold.

The findings of the present study suggest that septum may be involved in modulation of pain. The neurotransmitters like Acetylcholine, Noradrenaline and opioid peptides may have an individual or collective role to play in the observed pain modulation.
\end{abstract}

Keywords: Septum; Pain; Modulation; Neurotransmitters; Naloxone

\section{Introduction}

Major advances in past few decades have contributed immensely to the changing perceptions of how pain is integrated and modulated [14]. Studies have described a linear system of pain modulation involving the periaqueductal gray region (PAG) through the rostral ventromedial medulla (RVM) and descending to the spinal cord. We also envision pain as a complex matrix that includes important cortical regions and significant elements of the limbic system as well as the midbrain $[4,5]$.

Septum occupies a strategic position in limbic system, as it makes extensive connections with some parts of central nervous system, especially to important parts of limbic systems (e.g. hippocampus, cingulate, amygdale and hypothalamus). Septum has been implicated in variety of behaviors like aggression, sexuality and drinking [57]. Recently a study by Dutta et al. indicates that the medial septal glutamate receptors play an important role in the modulation of immune responses [8]. There are significant numbers of studies suggesting a probable role of septal nuclei in modulation of pain [918]. While the nature of neurochemical transmission involved in the septal nuclei which causes modulation of pain have not been explored previously. Therefore the present study has been undertaken to evaluate and confirm the role of septum in modulation of pain and the probable neurotransmitters involved in it. To know exactly which part of the septal nuclei is involved in modulation latero-medial portion was selected for lesioning in experimental rodents and subsequently testing them for pain responses. Various important neurotransmitters like opioid peptides, noradrenaline, acetylcholine, $\gamma$-aminobutyric acid, glutamate and somatostatin are involved in peripheral and spinal processing of pain [19-21]. The opioid system is chiefly concerned with the descending pathway, whether the same exists in the septal nuclei or there is non-opioid system involving neurotransmitters like acetylcholine and noradrenaline needs to be examined. Taking this fact into consideration in the present study we decided to focus on the three main modulating systems opioidinergic, cholinergic and adrenergic. As there are studies which suggest activation of muscarinic and nicotinic receptors produces analgesia in animal models of acute and chronic pain on one side, while on the other side the activation of adrenergic receptors in the dorsal horn of the spinal cord produces powerful analgesia in various animal models [22-27]. Although there are no noradrenergic neurons in the RVM or PAG, there is evidence that brain stem noradrenergic neurons contribute to the PAG-RVM inhibition of spinal nociceptive transmission [25,27]. Implantation of cannulae in septal nuclei and local injection of specific opioid blocker like naloxone and individual neurotransmitters was done to evaluate the pain modulating mechanisms.

\section{Material and Methods}

\section{Animals}

70 adult male wistar rats aged between 120-150 days (weighing 200-250 g) were used for the present studies. The surgical animals were housed in separate polyvinyl cages under 12 hour light and dark regime [light on at 600 hours and off at 1800 hours] and were fed with standard diet and water ad libitum. A prior permission was taken from the Institutional Ethics Committee of Rajarambapu College of Pharmacy, Kasegaon (RCPK) for use of rodents for the present research work. RCPK is registered under CPCSEA [Committee for the Purpose of Control and Supervision of Experiment on Animals]. The protocol of the present study was approved by the CPCSEA approved committee of RCPK. The experiments were performed according to the Ethical Guidelines of the International Association for the Study of Pain [28].

\section{Drugs}

Sodium pentobarbitone, acetylcholine, noradrenaline, scopolamine and naloxone were purchased from (Sigma St. Louis, U.S.A.). While

*Corresponding author: Prakash M. Somade, Professor, Department of Physiology Krishna institute of medical sciences, Karad, 415539. (Maharashtra), India, Tel: +9109890626369; E-mail: saishaprakash@gmail.com

Received September 08, 2015; Accepted October 17, 2015; Published October 19, 2015

Citation: Somade PM, Chopade AR, Brid SV (2015) Modulation of Pain by Naloxone and a Possible Role of Neurotransmitters with Selective Lesion of Septal Nuclei. J Spine 4: 263.doi:10.4172/2165-7939.1000263

Copyright: (c) 2015 Somade PM, et al. This is an open-access article distributed under the terms of the Creative Commons Attribution License, which permits unrestricted use, distribution, and reproduction in any medium, provided the original author and source are credited. 
all the other chemicals like Potassium ferrocynide, ferric chloride, formalin, alcohol were purchased from Research lab Mumbai.

\section{Stereotaxic Operative procedure for septal lesions and implantation of cannula}

Zero adjustment of the instrument: For precise localization of electrodes, the stereotaxic apparatus (INCO, Ambala, India) was adjusted properly with an anteroposterior scale, a lateral scale and a vertical scale for proper placement of electrodes. The ear bars were adjusted equally. The electrode carrier with dummy electrode was placed in between the two ear bars, taking care that the electrode was in a straight position. The readings of anteroposterior bar and lateral scale were noted for zero adjustment.

Lesioning procedure: Rats were anaesthetized with sodium pentobarbitone $35 \mathrm{mg} / \mathrm{kg}$ body weight, intraperitoneally and then were administered with atropine sulphate $2.5 \mathrm{mg} / \mathrm{kg}$ to minimize any respiratory discomfort. The anaesthetized rats were fixed properly on the stereotaxic apparatus with the help of ear bars. Then ear bars were inserted in clips and so adjusted that their distance on either side was equal and the head was in a fixed position. The incision of $1.5 \mathrm{~cm}$ length was made with razor blades on the skin of the skull starting at level behind the eyes, the membranous fascia covering the skull was cut away and the skull surface was exposed, so that external landmark of sutures become visible. The bregma was taken as reference point and with the use of stereotaxic co-ordinates; the sites to be implanted was marked with the ink using a dummy electrode. The holes were drilled at the marked points through the skull. The unipolar (anodal) electrode (28 gauge) varnished except at the tip was lowered stereotaxically in predetermined sites using previously reported co-ordinates. The other electrode (Neutral) was fixed to the ear of the animal. By using research stimulator S.S. 44 (Medicare), a D.C. anodal current of $1.5 \mathrm{~mA}$ intensity was passed for 20 seconds in lesion groups in a bilateral manner. In the sham operated group the electrode was lowered to septal nuclei but no current was passed. The co-ordinates for septal nuclei were as follows: $0.2 \mathrm{~mm}$ anterior to Bregma, $0.5 \mathrm{~mm}$ laterally on either side of sagittal suture, $5 \mathrm{~mm}$ deep below the surface of skull bones. After the procedure was over, the electrodes were removed from the skull and skin was sutured while the operative site was cleaned with spirit. Antiseptic powder was applied on dermal surface of the surgery and intramuscularly injection of Penicillin 10,000 I.U. was given. The operated animals were transferred to their respective cages for recovery.

Implantation of cannulae for intraseptal injection: A single 21 gauge guide cannula with stilet was introduced by stereotaxic technique into septum using following co-ordinates: $0.2 \mathrm{~mm}$ anterior to bregma, $0.5 \mathrm{~mm}$ lateral to midline suture and $5 \mathrm{~mm}$ deep. One screw was fixed over the skull in order to anchor cannula in its appropriate place. Dental cement was used for fixation of cannula and screw. The operative animals were given a time of one week to recover from operative trauma.

Intraseptal injections of neurotransmitter: The intraseptal injection of neurotransmitter under study was injected by using Hamilton syringe and slow injector pump. The microinjection was carried out by inserting the guide cannula which was a 26 gauge stainless steel needle connected to 5 ul Hamilton syringe by a polyethylene syringe. The tip of the injection jutted out from that of guide cannula by $1 \mathrm{~mm}$. The tail flick latencies of rats were studied after injection of neurotransmitters and naloxone in $0.9 \%$ saline.

Recording of tail flick latencies: The animals were held in a rat holder, with its tail protruding outside. 15 minutes adaptation period was allowed. $1 \mathrm{~cm}$ segment of the rat's tail, $5 \mathrm{~cm}$ away from the tip of the tail was kept in the groove of the water jacket above the nichrome wire of Analgesiometer (Techno Mark IV). The analgesiometer was switched on and the timer was set to zero. The A.C. current of 3.5 ampere was passed through the nichrome wire by pressing the foot switch. This also simultaneously stated the timer.

The moment the rat flicks its tail due to pain, the foot switch was pressed again to stop the timer and switch off the current through the nichrome wire to allow further injury the rat. The reading on the timer in seconds was considered as the tail flick latency. There readings were taken at an interval 15 minutes and average mean of three readings was calculated. The tail flick latencies were recorded for all the experimental groups. A cut off time of 30 seconds was fixed to avoid damage to the tail of the rats.

\section{Experimental protocol}

The operated animals were observed for 7-8 post operatively when the aggressive behavior or such affective response disappeared. The present study was divided in two parts in first part the tail flick latencies were observed in rats with bilateral septal lesions and compared with sham operated ones. While in the second part, the effect of intraseptal injections of neurotransmitters and naloxone on tail flick latencies was recorded after intraseptal lesions.

The rats were divided into seven groups of ten animals each as follows: group I - rats with bilateral septal lesions; group II - sham operated rats; group III - cannulated rats serving as control treated with 2 ul vehicle [0.9\% saline] intraseptally; group IV - cannulated rats treated with Acetylcholine 5 ug intraseptally; group V - cannulated rats treated with Scopolamine 5 ug; group VI - cannulated rats treated with Noradrenaline 5 ug intraseptally; and group VII - cannulated rats treated with Naloxone $5 \mathrm{ug}$ intraseptally.

The rational basis for selecting the equal amount of doses such as 5 $\mu \mathrm{g}$ for all the drugs used in the present study was drawn from previous reports and a previous study from our lab [14].

In the groups injected with neurotransmitters intraseptally all the neurotransmitters ( $5 \mathrm{ug}$ ) were dissolved in $2 \mathrm{ul}$ of $0.9 \%$ saline, over a period of 60 seconds and the needle was held in place for about another 60 seconds after injection.

\section{Histological studies}

At the end of the experiment septallylesioned rats were sacrificed by large dose of pentobarbitone given intraperitoneally. The brain was taken out and kept in 10\% formalin for hardening and later subjected to histological examination to evaluate the site and extent of lesion by Prussian blue reaction. The septal sections were kept in $3 \%$ of potassium ferrocyanide solution after Prussian blue reaction at the site of lesion to determine extent of diffusion of neurotransmitter [29].

\section{Statistical analysis}

The mean of tail flick latencies in sham operated and septallylesionsed rats were calculated and students ' $t$ ' test was applied to assess the level of significance in observed differences. Two way repeated measures Analysis of variance (ANOVA) was used to see if the differences observed in tail flick latencies after injection of various neurotransmitters in individual groups were significant or not as compared to the saline (vehicle) treated groups followed by Tukey's multiple comparison test, to test the level of significance. 


\section{Results}

\section{Effects on tail flick latencies in rats with bilateral septal lesions and sham operated ones}

Animals exhibited phenotype indications of distress after the electrolytic lesion of the septum for first five days after the surgical procedure. So the tail flick latencies were recorded on the eighth day when the sterotyphic and phenotyphic signs were abolished. The effect of septal lesions on tail flick latencies in rats was studied in Group I septallylesioned $(n=10)$ and Group II sham operated $(n=10)$. The results of the present study show that in septallylesioned rats the tail flick latencies were reduced considerably as compared to sham operated group $(\mathrm{P}<0.01)$, for details see Figure 1 .

\section{Effects of intraseptal injection of naloxone}

In the attempt to explore the possible role of opioidnergic system in septum on pain modulating reaction of the rats, Naloxone $(5 \mu \mathrm{g}, 10 \mu \mathrm{g}$ and $20 \mu \mathrm{g}$ ) was injected intraseptally and was compared for thetail flick latencies with the saline group, the comparative results are depicted in

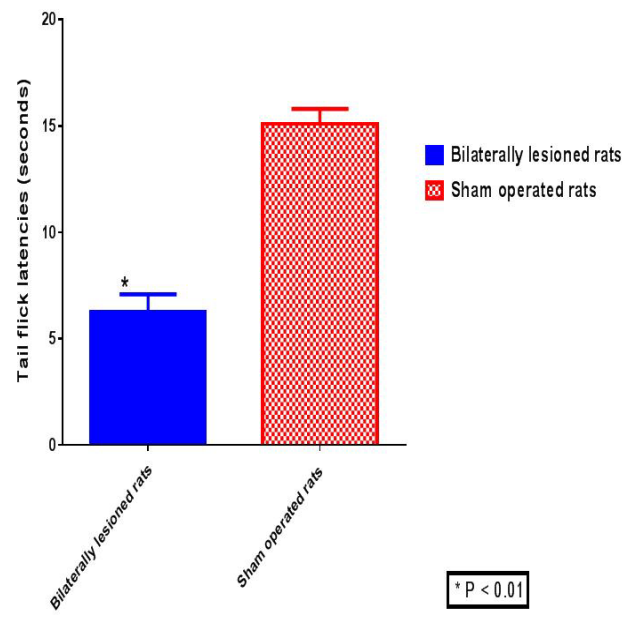

Figure 1: Effect of bilateral septal lesions and sham operated rats on tail flick latencies. Data are represented as mean \pm standard deviation $n=10$ for both the groups. Significant differences relative to the bilateral septal lesioned group are indicated as $\mathrm{P}<0.01$

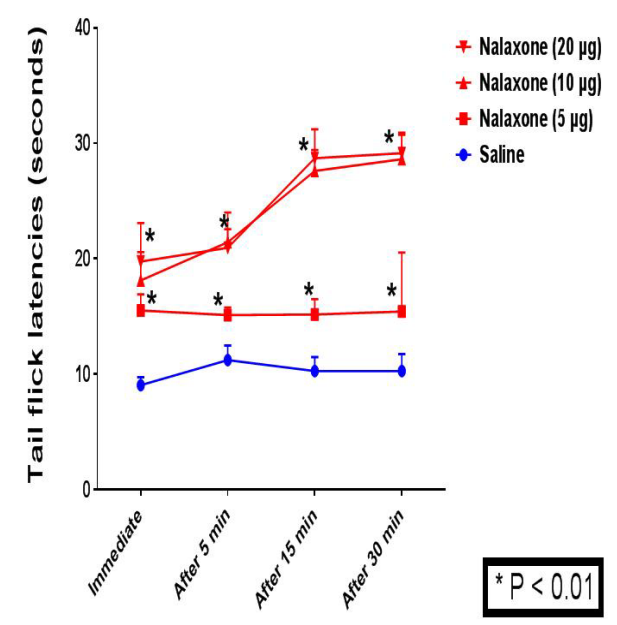

Figure 2: Effects of intraseptal administration of nalaxone on hea hypersensitivity in septally lesioned rats. Each point represents the mean \pm SEM of the tail flick latency (in seconds) at the indicated time points. $P<0.01$ denotes the significance levels in comparison to saline treated group $(n=5)$.

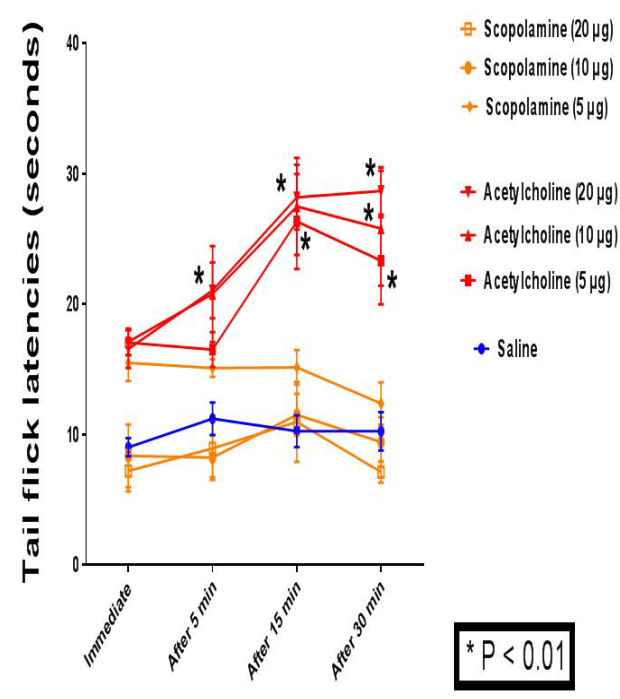

Figure 3: Effects of intraseptal administration of Acetylcholine and Scopolamine on heat hypersensitivity in septally lesioned rats. Each point represents the mean \pm SEM of the tail flick latency (in seconds) at the indicated time points. $\mathrm{P}<0.01$ denotes the significance levels in comparison to saline treated group $(n=5)$

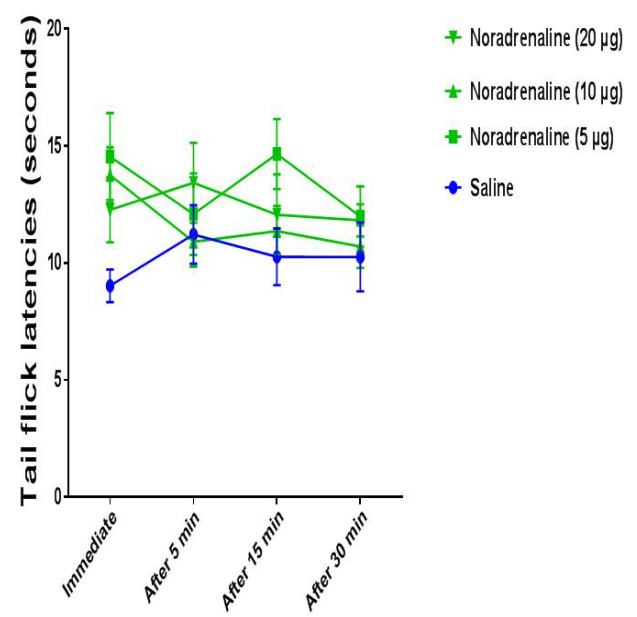

Figure 4: Effects of intraseptal administration of Noradrenaline on heat hypersensitivity in septally lesioned rats. Each point represents the mean \pm SEM of the tail flick latency (in seconds) at the indicated time points. $P<0.01$ denotes the significance levels in comparison to saline treated group $(n=5)$.

Figure 2. In naloxone treated group the tail flick latencies increased after 15 and 30 minutes $(\mathrm{P}<0.01)$. These findings are rather contradictory to the general belief that naloxone blocks opiate analgesia.

\section{Effects of intraseptal injections of neurotransmitters}

Toexplore the possible role of various neurotransmitters in septum on pain modulating reaction of the rat's acetylcholine and noradrenaline were injected intraseptally and all the groups were compared for their tail flick latencies with the saline group, the comparative results are depicted in Figures 3 and 4.

In the Acetylcholine injected group it was seen that although tail flick latencies was increased immediately and after 5 minutes but they were not statistically significant. However, the tail flick latencies increased after 15 and 30 minutes $(\mathrm{P}<0.01)$ were statistically significant. In scopolamine injected group it was seen that the tail flick latencies 
decreased immediately, after 5 minutes and after 15 minutes of injection and was normalized after 30 minutes. In the Noradrenaline treated group the tail flick latencies increased after the intra septal injection but were not statistically significant.

\section{Discussion}

To summarize the results of the present study it was observed that the septal lesions decrease pain threshold. The interaseptal injection of acetylcholine and naloxone in septum increases pain threshold. While the interaseptal injection of noradrenaline and scopolamine decreases pain threshold.

In the present study, septallylesioned rats exhibited decreased tail flick latencies indicating that septum may be involved in modulation of pain. It was previously observed that somatosensory stimulation could elicit bursting activity in the septum [30-33]. Further the septal neurons are sensitive to pain stimulation as noted by Dutar et al., that majority of septohippocamal neurons in rats are activated by noxious stimuli [18]. Stimulation of septal region can modify the consequences of painful stimulations, impair conditioned emotional response learning and can attenuate acquisition of passive avoidance response [34]. The efferent, afferent and intrinsic connections of the septal nuclei have been analyzed in systematic studies and also by the autoradiographic method in rats $[12,35]$. The effects of the stimulation of lateral and medial septum with the single pulses of current were assessed on the neural activity evoked by a noxious tail shock as well as spontaneous activity in 72 cells located in periventricular nuclei, PAG, dorsal raphe and nucleus raphe magnus of anaesthetized rats [36]. Pronounced inhibitory effects of evoked activity were found primarily in dorsal raphe and PAG. Inhibitory effects on dorsal horn neurons responding to noxious stimuli have been reported by stimulation of septal areas in the cat [37]. Studies have demonstrated the fact that the septal nuclei have increased in prominence throughout the primates and have reached their highest degree of primate development in the human brain [38]

As the direct connections of septal nuclei with dorsal horn cells have not been reported, nor do the ascending pain pathways pass through the septum, it is difficult to explain the mechanism by which septal nuclei increase the pain threshold. However, indirect connection of septal nuclei with descending analgesic pathway may explain modulation of pain by the septum. The ventral part of the lateral septal nucleus sends fibers through medial forebrain bundle to the various nuclei of hypothalamus mammillary body and to the ventral tegmental area. Similarly the medial septal nuclei also send fibers to the ventral tegmental area in the midbrain and raphe nuclei [12]. The septal nucleus is closely connected to the most important component of descending analgesic system i.e. ventral tegmental area and nucleus raphe magnus. It is possible that the septal nuclei may be tonically activating descending analgesic system through these connections and modifies the pain reactions of the animal. The issue needs to be resolved by correlating unit activity from septum, ventral tegmental area and nucleus raphe magnus during rest and after painful stimuli.

Our study with naloxone an opioid receptor blocker has produced results contrary to the general belief, as it exhibited analgesic effect after its administration in the septal area. Previous study has shown that micro injection of morphine $(10 \mu \mathrm{g})$ into unilateral septal nucleus had no obvious effect on the pain threshold; also the effect of electroacupuncture was remarkably prolonged by injecting Thyroid Releasing Hormone $(1.5 \mu \mathrm{g})$ into unilateral septal nucleus [39]. If the endogenous opioids are involved in intrinsic mechanisms of pain inhibition and naloxone antagonizes all opioid like substances, then naloxone itself should produce a hypersensitivity to painful stimuli.
This hyperalgesic effect has been demonstrated in humans [40] and animals [41] supporting the notion that naloxone antagonizes a tonic, opioid mediated inhibition of nociception. The intraseptal injection of morphine and pentazocine also had no effect on pain threshold after septal lesions, however our study indicates that interaseptal injection of naloxone produces analgesia.

Vaccarina et al., have reported naloxone induced analgesia in BALB/C mice with formalin test and have suggested that the effect is mediated via an opioid system [42]. They also proposed that naloxone analgesia may result from naloxone acting as an agonist or a partial agonist at a subpopulation of opioid receptor that are more prominent in the BALB/C mice. It is possible that while naloxone has affinity as an antagonist for receptors responsible for morphine analgesia, at higher doses it may behave as an agonist at another set of opioid receptors to produce analgesia independent of morphine's site of action. Synergism between morphine and naloxone has previously been demonstrated in human and the partial opiate agonist buprenorphine, has also been reported to have similar effect when combined with naloxone [43]. Furthermore, microinjections of morphine have been reported to produce both analgesia and hyperalgesia in the rat with both effects being reversed by naloxone [44]. Gillman and Licthigfield have proposed a dual system hypothesis of pain perception to explain these findings. They suggest the existence of two opposing opioid systems [45]. One of which decreases pain and other one that enhances it. Vaccarina et al., have suggested that naloxone analgesia is independent of naloxone antagonism of morphine analgesia in formalin test and is dosing related [43]. Such a hypothesis provides a means for reconciling the present data with the role of naloxone in septum. It is possible that intraseptal injection of naloxone in graded doses may block kappa receptors in septum and potentiate action of endogenous opioids on $\mathrm{mu}$ receptors. However, elucidation of these mechanisms requires further experimentation.

Present study was also designed to see the possible role of some common neurotransmitters in septal regulation of pain perception. In our study intraseptal injection of acetylcholine increased the tail flick latencies in rats as compared to saline group. Which indicates that acetylcholine decreases the pain threshold. Acetylcholine is one of the main neurotransmitters released in the neocortex and hippocampus [25]. Acetylcholine in the cerebral cortex is derived from the basal forebrain, with the nucleus basalis innervating the neocortex and the medial septum and vertical limb of the diagonal band innervating the hippocampus and entorhinal cortex $[7,25]$. The basal forebrain cholinergic nuclei are comprised of the medial septal nucleus, while it is also know that cholinergic fibers from septum project to various areas including ventral tegmental and PAG [27]. Both these areas are important component of descending analgesic system. Thus the intraseptal injection of acetylcholine may have stimulated the descending analgesic system. To confirm these results we used cholinergic blocker scopolamine. As expected there was decrease in tail flick latencies after intraseptal injections of scopolamine in rats.

Nor adrenaline has a widely demonstrated role in pain modulation and is a main neurotransmitter in locus coeruleus, one of the major components of the descending pain pathways [28]. Similarly there are reports, describing seemingly contradictory results regarding the involvement of noradrenaline in morphine analgesia [28]. It is worth pointing out that both tramadol and tapentadol are opioids which also are potent noradrenaline reuptake inhibitors and are used clinically as analgesics [46,47] and a similar mechanism might be active in septum [48]. However, the present study needs further evaluation together by using specific blockers along with simultaneous electrophysiological studies. 
Citation: Somade PM, Chopade AR, Brid SV (2015) Modulation of Pain by Naloxone and a Possible Role of Neurotransmitters with Selective Lesion of Septal Nuclei. J Spine 4: 263.doi:10.4172/2165-7939.1000263

Page 5 of 5

To conclude the outcomes of the present study confirm that the septum may be involved in modulation of pain and neurotransmitters like Acetylcholine, Noradrenaline and opioid peptides may have an individual or collective role to play in modulation of pain.

\section{Conflicts of Interest}

We all the authors declare no conflict of interest.

\section{References}

1. Basbaum Al, Bautista DM, Scherrer G, Julius D (2009) Cellular and molecular mechanisms of pain. Cell 139: 267-284.

2. Burgess G, Williams D (2010) The discovery and development of analgesics: new mechanisms, new modalities. J Clin Invest 120: 3753-3759.

3. Schweinhardt P, Bushnell MC (2010) Pain imaging in health and disease--how far have we come? J Clin Invest 120: 3788-3797.

4. Ossipov MH, Dussor GO, Porreca F (2010) Central modulation of pain. J Clin Invest 120: 3779-3787.

5. Jensen MP, Day MA Miró J (2014) Neuromodulatory treatments for chronic pain: efficacy and mechanisms. Nat Rev Neurol 10: 167-178.

6. Myers RD (1990) Anatomical "circuitry" in the brain mediating alcohol drinking revealed by THP-reactive sites in the limbic system. Alcohol 7: 449-459.

7. Tai SiewKian, Ma Jingyi, Stan Leung L (2014) Medial Septal Cholinergic Neurons Modulate Isoflurane Anesthesia Anesthesiology 120: 392-402.

8. Dutta G, Raj Goswami A, Ghosh T (2013) Effects of stimulation of glutamate receptors in medial septum on some immune responses in rats. Brain Res 1538: $116-125$

9. Gol A (1967) Relief of pain by electrical stimulation of the septal area. J Neurol Sci 5: 115-120.

10. Lico MC, Hoffmann A, Covian MR (1974) Influence of some limbic structures upon somatic and autonomic manifestations of pain. Physiol Behav 12: 805811

11. Abbott FV, Melzack R (1978) Analgesia produced by stimulation of limbic structures and its relation to epileptiform after-discharges. Exp Neurol 62: 720734

12. Swanson LW, Cowan WM (1979) The connections of the septal region in the rat. J Comp Neurol 186: 621-655

13. Oleson TD, Kirkpatrick DB, Goodman SJ (1980) Elevation of pain threshold to tooth shock by brain stimulation in primates. Brain Res 194: 79-95.

14. Chitale MS (1994) The role of septal nuclei in modulation of pain in rats, A dissertation for MD Physiology. Shivaji University Kolhapur 50-62.

15. Khanna S (1997) Dorsal hippocampus field CA1 pyramidal cell responses to a persistent versus an acute nociceptive stimulus and their septal modulation. Neuroscience 77: 713-721.

16. Leung LS, Ma J, Shen B, Nachim I, Luo T (2013) Medial septal lesion enhances general anesthesia response. Exp Neurol 247: 419-428.

17. Zheng F, Khanna S (2001) Selective destruction of medial septal cholinergic neurons attenuates pyramidal cell suppression, but not excitation in dorsa hippocampus field CA1 induced by subcutaneous injection of formalin. Neuroscience 10: 985-998.

18. Dutar P, Lamour Y, Jobert A (1985) Activation of identified septo-hippocampal neurons by noxious peripheral stimulation. Brain Res 328: 15-21.

19. Budai $D$ (2000) Neurotransmitters and receptors in the dorsal horn of the spinal cord. ActaBiologicaSzegediensis 44: 21-38.

20. Pan HL, Wu ZZ, Zhou HY, Chen SR, Zhang HM, et al. (2008) Modulation of pain transmission by G-protein-coupled receptors. Pharmacol Ther 117: 141-161.

21. Al-Hashimi M, Scott SW, Thompson JP, Lambert DG (2013) Opioids and immune modulation: more questions than answers. Br J Anaesth 111: 80-88.

22. Xie CW, Tang J, Han JS (1983) Central norepinephrine in acupuncture analgesia: different effects in the rat brain and spinal cord. ActaPhysiol Sin 35 : 186-190.

23. Reddy SV, Yaksh TL (1980) Spinal noradrenergic terminal system mediates antinociception. Brain Res 189: 391-401.
24. Eisenach JC (1999) Muscarinic-mediated analgesia. Life Sci 64: 549-554.

25. Phillis JW (2005) Acetylcholine release from the central nervous system: a 50 year retrospective. Crit Rev Neurobiol 17: 161-217.

26. Wang Y, Feng C, Wu Z, Wu A, Yue Y (2008) Activity of the descending noradrenergic pathway after surgery in rats. Acta Anaesthesiol Scand 52: 13361341.

27. Malenka RC, Nestler EJ, Hyman SE (2009) Chapter 6: Widely Projecting Systems: Monoamines, Acetylcholine, and Orexin". In: Sydor A, Brown RY (eds.) Molecular Neuropharmacology: A Foundation for Clinical Neuroscience (2nd edn), New York: McGraw-Hill Medical. pp. 167-175.

28. Zimmermann M (1983) Ethical guidelines for investigations of experimenta pain in conscious animals. Pain 16: 109-110.

29. Sheehan D, Hrapchak B (1980) Theory and practice of histotechnology. (2nd edn), Battelle Press: Ohio, 217-218.

30. Apostol G, Creutzfeldt OD (1974) Crosscorrelation between the activity of septal units and hippocampal EEG during arousal. Brain Res 67: 65-75.

31. Matsumura H, Nakajima T, Osaka T, Satoh S, Kawase K, et al. (1994) Prostaglandin D2-sensitive, sleep-promoting zone defined in the ventral surface of the rostral basal forebrain. Proc Natl Acad Sci U S A 91: 11998-12002.

32. Assaf SY, Miller JJ (1978) The role of a raphe serotonin system in the control of septal unit activity and hippocampal desynchronization. Neuroscience 3: 539-550.

33. Petsche H, Stumpf C, Gogolak G (1962) The significance of the rabbit's septum as a relay station between the midbrain and the hippocampus. I. The contro of hippocampus arousal activity by the septum cells. Electroencephalogr Clin Neurophysiol 14: 202-211.

34. Kasper P (1964) Attenuation of passive avoidance by continuous septa stimulations. Psychoneur. Sci 1: 219-220.

35. Raisman G (1966) The connexions of the septum. Brain 89: 317-348.

36. De Nasi PC, Thomas E (1982) The effects of septal stimulation on spontaneous and tail-shock evoked neuronal activity in the brainstem of the rat. Brain Res 249: 63-71.

37. Carstens E, MacKinnon JD, Guinan MJ (1982) Inhibition of spinal dorsal horn neuronal responses to noxious skin heating by medial preoptic and septa stimulation in the cat. J Neurophysiol 48: 981-989.

38. Andy OJ, Stephan H (1968) The septum in the human brain. J Comp Neurol 133: 383-410.

39. Tu Z, Zhang Z, Zhu Z (1990) [The effects of microinjection of TRH or morphine into unilateral nucleus septum on pain threshold and electroacupuncture analgesia in rats]. Zhen Ci Yan Jiu 15: 6-12.

40. Levine JD, Gordon NC, Fields HL (1979) Naloxone dose dependently produces analgesia and hyperalgesia in postoperative pain. Nature 278: 740-741.

41. Grevert P, Goldstein A (1978) Endorphins: naloxone fails to alter experimental pain or mood in humans. Science 199: 1093-1095.

42. Vaccarino AL, Tasker RA, Melzack R (1988) Systemic administration of naloxone produces analgesia in BALB/c mice in the formalin pain test. Neurosc Lett 84: 103-107.

43. Vaccarino AL, Tasker RA, Melzack R (1989) Analgesia produced by normal doses of opioid antagonists alone and in combination with morphine. Pain 36 103-109.

44. Jacquet YF, Lajtha A (1974) Paradoxical effects after microinjection of morphine in the periaqueductal gray matter in the rat. Science 185: 1055-1057.

45. Gillman MA, Kimmel I, Lichtigfeld FJ (1981) The dual-system hypothesis of pain perception. Neurol Res 3: 317-327.

46. Grond S, Sablotzki A (2004) Clinical pharmacology of tramadol. Clin Pharmacokinet 43: 879-923.

47. Tzschentke TM, Jahnel U, Kogel B, Christoph T, Englberger W, et al. (2009) Tapentadol hydrochloride: a next-generation, centrally acting analgesic with two mechanisms of action in a single molecule. Drugs Today (Barc) 45: 483-496.

48. Tracey I, Mantyh PW (2007) The cerebral signature for pain perception and its modulation. Neuron 55: 377-391. 